\title{
Alteration of Long-lasting Structural and Functional Effects of Kainic Acid in the Hippocampus by Brief Treatment with Phenobarbital
}

\author{
Thomas Sutula, Jose Cavazos, and Golijeh Golarai \\ The Neuroscience Training Program and the Departments of Neurology and Anatomy, University of Wisconsin, Madison, \\ Wisconsin 53792
}

Kainic acid, an analog of the excitatory amino acid L-glutamate, induces acute hyperexcitability and permanent structural alterations in the hippocampal formation of the adult rat. Administration of kainic acid is followed by acute seizures in hippocampal pathways, neuronal loss in CA3 and the hilus of the dentate gyrus, and reorganization of the synaptic connections of the mossy fiber pathway. Rats with these hippocampal structural alterations have increased susceptibility to kindling. To evaluate the role of the acute seizures and associated hippocampal structural alterations in the development of this long-lasting susceptibility, rats that received intraventricular kainic acid were cotreated with phenobarbital (60 $\mathrm{mg} / \mathrm{kg}$, s.c., once daily). Treatment with this dose for $5 \mathrm{~d}$ after administration of kainic acid suppressed acute seizure activity, protected against excitotoxic damage in the dentate gyrus, reduced mossy fiber sprouting, and completely abolished the increased susceptibility to kindling associated with kainic acid. Brief treatment with phenobarbital modified the pattern of damage and synaptic reorganization in the dentate gyrus in response to seizureinduced injury, and altered the long-lasting functional effects associated with hippocampal damage. As phenobarbital treatment did not protect against neuronal damage in CA3 or other regions of the hippocampus, the circuitry of the dentate gyrus was implicated as a locus of cellular alterations that influenced the development of kindling. These observations are evidence that pharmacological intervention can prevent the development of epilepsy in association with acquired structural lesions, and suggest that pharmacological modification of cellular responses to injury can favorably alter long-term functional effects of CNS damage.

Pathways in the CNS undergo reorganization of synaptic connections in response to a variety of experimental lesions (Cotman et al., 1981). For example, in the hippocampal formation, kainic acid (KA) induces neuronal loss in CA3, CA1, and the hilus of the dentate gyrus (DG), which is accompanied by sprouting and synaptic reorganization of the mossy fiber pathway. In addition, there is now evidence that brief seizures evoked by kindling (Goddard et al., 1969) also induce neuronal loss in the hilus of the DG, which is accompanied by sprouting and per-

\footnotetext{
Received Mar. 24, 1992; revised May 19, 1992; accepted June 1, 1992.

This work was supported by NINDS Grant R29-NS25020. We appreciate the technical assistance of Cynthia Hurtenbach and Barbara Darcey.

Correspondence should be addressed to T. Sutula, Department of Neurology, H4/614, University of Wisconsin, Madison, WI 53792.

Copyright (C) 1992 Society for Neuroscience 0270-6474/92/124173-15\$05.00/0
}

manent reorganization of the synaptic connections of the mossy fiber pathway (Sutula et al., 1988; Cavazos and Sutula, 1990, 1991; Cavazos et al., 1991). Physiological studies have demonstrated that sprouted pathways can reestablish functional synaptic transmission (Steward et al., 1973, 1976; Tauck and Nadler, 1985), but the specific effects of mossy fiber sprouting and other forms of synaptic reorganization on the physiological properties and function of hippocampal circuitry are uncertain.

The structural alterations induced by KA have attracted considerable attention, as similar patterns of neuronal loss and synaptic reorganization have been observed in hippocampal sclerosis, a lesion frequently associated with human epilepsy (Babb and Brown, 1987; Sutula, 1990). The role of hippocampal sclerosis as a cause or effect of epilepsy has been controversial for more than a century, but the neuronal loss and synaptic reorganization in the KA-treated hippocampus are accompanied by hyperexcitability (Franck and Schwartzkroin, 1985; Tauck and Nadler, 1985; Franck et al., 1988), spontaneous seizures (Cronin and Dudek, 1988), and increased susceptibility to development of epilepsy by kindling (Feldblum and Ackermann, 1987; Sutula et al., 1987). Because the increased susceptibility to kindling has been observed as long as $3-4$ months after induction of a hippocampal lesion by KA (Sutula et al., 1987), it was of interest to identify the specific alterations induced by KA that play a role in this long-lasting increased susceptibility.

In vivo administration of KA induces a complex sequence of functional and structural alterations that develop with a predictable time course in the hippocampus and other structures of the CNS (Ben-Ari, 1985). Systemic, intraventricular, or intraparenchymal administration of $\mathrm{KA}$ induces intense continuous seizure activity in limbic pathways that resembles status epilepticus (Lothman et al., 1981; Ben-Ari, 1985). The acute seizures induced by KA are nearly continuous for $48 \mathrm{hr}$, but gradually resolve within 4-5 d after administration (Ben-Ari, 1985). Neuronal degeneration in the hilus and inner molecular layer of the DG develops within hours to days after administration of KA, and histological evidence of mossy fiber sprouting and synaptogenesis in the denervated inner molecular layer becomes evident 7-10 d later (Nadler and Cuthbertson, 1980; Nadler et al., 1980a,b; Laurberg and Zimmer, 1981).

The time course for development of increased susceptibility to kindling after administration of KA may provide a clue about the cellular and molecular alterations in hippocampal circuitry that play a role in the induction of kindled scizurcs. The possible causes for the increased susceptibility to kindling after administration of $\mathrm{KA}$ include acute alterations such as seizures or neuronal loss, or more slowly developing structural alterations 
such as sprouting and synaptic reorganization. As the increased susceptibility to kindling is present as early as 1-2 weeks after administration of KA (Feldblum and Ackerman, 1987), the acute seizures, neuronal loss, or synaptic reorganization occurring in the 2 weeks after administration of KA might play an important role in the increased susceptibility to development of epilepsy by kindling.

The purposes of this study were (1) to evaluate the role of acute KA-induced seizure activity in the long-lasting increased susceptibility to kindling associated with hippocampal lesions, and (2) to consider whether structural alterations in hippocampal circuitry, independently of KA-induced seizures, play a role in the long-lasting increased susceptibility. Rats were treated with the anticonvulsant phenobarbital after intraventricular injection of KA. The effects of phenobarbital on acute seizure activity, neuronal degeneration, mossy fiber synaptic reorganization, and the rate of kindling development were evaluated.

A preliminary report has appeared in abstract form (Sutula et al., 1990).

\section{Materials and Methods}

Administration of kainic acid. After induction of anesthesia with pentobarbital (50 $\mathrm{mg} / \mathrm{kg}$, i.p.), Sprague-Dawley male rats (300-350 gm) received a unilateral intraventricular injection of $\mathrm{KA}(0.5-0.75 \mathrm{gm}$ in $0.5-0.75 \mu$ l of deionized $\mathrm{H}_{2} \mathrm{O}$ ) via a Hamilton syringe, according to published techniques (Franck and Schwartzkroin, 1985). Rats that received KA were randomly divided into groups that received phenobarbital at a variety of doses and for variable intervals. Normal unlesioned rats and rats that received only KA served as controls.

Administration of phenobarbital. Rats that received phenobarbital werc divided into groups that reccived cither a dose of $60 \mathrm{mg} / \mathrm{kg}$ or $30-$ $40 \mathrm{mg} / \mathrm{kg}$. The first dose was administered by intraperitoneal injection immediately after unilateral intraventricular injection of KA. On subsequent days, each rat received phenobarbital at the designated dose by subcutaneous injection at a fixed time each day (about 2 P.M.). This administration schedule was chosen because previous studies have revealed that the half-life of phenobarbital is about $8-9 \mathrm{hr}$ in SpragueDawley male rats, and the estimated average steady state phenobarbital level in rats treated with the $60 \mathrm{mg} / \mathrm{kg}$ dosage was about $55 \mu \mathrm{g} / \mathrm{ml}$ (Rouse-Brouwer et al., 1984a,b). Phenobarbital levels in the range of $15-40 \mu \mathrm{g} / \mathrm{ml}$, or about $120 \mathrm{~mm}$, have been associated with anticonvulsant effects in vivo, and suppression of repetitive firing in vitro (MacDonald and McLean, 1986). In a previous study, a single dose of phenobarbital $(60 \mathrm{mg} / \mathrm{kg}$, i.p.) was also reported to be effective as an anticonvulsant against KA-induced seizures during the first $24 \mathrm{hr}$ after intraparenchymal injection of KA into hippocampus (Feldblum and Ackermann, 1987).

Procedures for monitoring KA-induced epileptic activity. A subset of rats cotreated with $\mathrm{KA}$ and phenobarbital were implanted with electrodes in the DG for monitoring KA-induced epileptic activity. Surgical anesthesia was maintained in these rats with an initial dose of pentobarbital $(50 \mathrm{mg} / \mathrm{kg}, \mathrm{i} . \mathrm{p}$.), followed by supplemental intraperitoneal doses of $5 \mathrm{mg} / \mathrm{kg}$, as necessary. The anesthetized rats were then implanted with a stainless steel electrode for chronic recording in the DG $(3.3 \mathrm{~mm}$ posterior, $1.7 \mathrm{~mm}$ lateral, $3.5 \mathrm{~mm}$ deep to bregma). This electrode was insulated except at the exposed recording surface near the tip, and was fixed to the skull with acrylic.

The spontaneous EEG from the DG in the anesthetized rats was prcamplificd by a field-effect transistor in a headstage, recorded by differential AC amplifiers referenced to ground, and displayed on a polygraph for $15 \mathrm{~min}$ as a baseline period of control recording prior to intraventricular injection of $\mathrm{KA}$. The rats then received intraventricular $\mathrm{KA}$, which was immediately followed by intraperitoneal phenobarbital at doses of either $60 \mathrm{mg} / \mathrm{kg}$ or $30-40 \mathrm{mg} / \mathrm{kg}$. The spontaneous EEG was continuously recorded from the DG for $8 \mathrm{hr}$.

On days 2-4 after KA injection, the EEG was also recorded from the DG for 15 min daily just prior to administration of the next dose of phenobarbital (i.e., 2 P.M.). This recording schedule provided a sample of electrographic activity corresponding to the trough level of phenobarbital.

Measurement of phenobarbital levels. Steady state trough plasma phenobarbital levels were measured in the phenobarbital-treated rats that were studied with EEG recording. At $24 \mathrm{hr}$ after the last dose of phenobarbital on day 14 after $\mathrm{KA}$ injection, these rats were deeply anesthetized with pentobarbital $(50 \mathrm{mg} / \mathrm{kg}$, i.p.). The steady state trough plasma levels of phenobarbital were obtained from venous blood just prior to perfusion for histological examination. Plasma phenobarbital levels were determined by capillary column gas chromatography with flame ionization detection, calibrated to known concentrations of phenobarbital. Pentobarbital did not interfere with the assay method.

Timm histochemistry. The distribution of lesions induced by KA was assessed by examination of neuronal loss and gliosis in cresyl violetstained horizontal sections of the hippocampal formation. Lesion-induced synaptic reorganization of the mossy fiber pathway was evaluated in experimental and control groups by Timm histochemistry. Synaptic reorganization of the mossy fiber pathway can be easily observed with the Timm method, a histochemical technique that labels the synaptic terminals of the mossy fibers due to their high content of $\mathrm{Zn}$ (Danscher, 1981; Frederickson et al., 1983; Danscher et al., 1985). Details of perfusion, fixation, and histological methods for cresyl violet staining and Timm histochemistry are available in previous publications (Sutula et al., 1988; Cavazos et al., 1991).

Scoring methods for Timm histochemistry. The extent of mossy fiber sprouting and synaptic reorganization in rats that achieved only KA and rats that were cotreated with phenobarbital was analyzed independently by three observers who were unaware of the identity of each brain section, using a previously published, standardized scoring procedure (Cavazos et al., 1991). Kindled rats in this study were not evaluated by the scoring methods for Timm histochemistry, but have been reported in a previous publication that also includes the theoretical basis, procedures, and statistical analysis for this method (Cavazos et al., 1991). Rats with depth electrodes for recording in the DG were included in the scoring analysis.

Mossy fiber synaptic reorganization was evaluated by rating the distribution of Timm granules, which correspond to synaptic terminals of the mossy fiber pathway, in the supragranular layer at standardized locations in the dorsal (septal) and ventral (temporal) DG, as described in previous publications (Cavazos et al., 1991, 1992) The distribution of Timm granules in the supragranular region was rated on a scale of 0 to 5 according to the following criteria:

$0-$ No granules between the tips and crest of the DG.

1 -Sparse granules in the supragranular region in a patchy distribution between the tips and crest of the DG.

2-More numerous granules in the supragranular region in a continuous distribution between the tips and crest of the DG.

3-Prominent granules in the supragranular region in a continuous pattcrn between tips and crest, with occasional patches of confluent granules between tips and crests of the DG.

4-Prominent granules in the supragranular region that form a confluent dense laminar band between tips and crest.

5 -Confluent dense laminar band of granules in the supragranular region that extends into the inner molecular layer.

A Timm score was calculated for each rat by averaging the independently derived scores of the three observers at the septal and temporal locations. Mean Timm scores for experimental and control groups were calculated by averaging the Timm scores of each animal in a given group. The differences in mean Timm scores between experimental and control groups were analyzed for statistical significance with the two-tailed Student's $t$ test.

Fink-Heimer histochemistry. The Fink-Heimer method (method II in de Olmos et al., 1981) was used to assess neuronal and terminal degeneration in additional groups of rats that received only intraventricular KA, or KA followed by phenobarbital $(60 \mathrm{mg} / \mathrm{kg})$ once daily for $3 \mathrm{~d}$. Rats in these groups were perfused with a $10 \%(\mathrm{w} / \mathrm{v})$ solution of formalin on the third day after intraventricular injection of KA. Details of the Fink-Heimer method are available in previous publications (Fink and Heimer, 1967; de Olmos et al., 1981).

Surgical procedures and stimulation methods for perforant path kindling. Another group of rats were implanted with a twisted Teflon-coated stainless steel bipolar electrode $(0.15 \mathrm{~mm}$ diameter) for chronic stimulation and recording in the perforant path near the region of the angular bundle $(8.1 \mathrm{~mm}$ posterior, $4.4 \mathrm{~mm}$ lateral, $3.5 \mathrm{~mm}$ deep to bregma), and were then cotreated with KA and phenobarbital. After KA injection and implantation of the electrodes, rats in this group received phenobarbital in doses of either $60 \mathrm{mg} / \mathrm{kg}$ or $30 \mathrm{mg} / \mathrm{kg}$ once daily for $5 \mathrm{~d}$. 
Two weeks after KA injection and implantation of the electrodes, and $9 \mathrm{~d}$ after the last dose of phenobarbital, kindling was induced according to standard methods described in previous publications (Goddard et al., 1969; Sutula and Steward, 1986; Sutula et al., 1988). Normal unlesioned rats that did not receive phenobarbital served as controls.

A potential confounding feature of this experiment was the possibility that phenobarbital might delay the development of kindled seizures by direct anticonvulsant action against evoked afterdischarge (AD) at the time of the initial kindling stimulation 2 weeks after KA administration. This possibility was unlikely based on pharmacokinetics of phenobarbital in the Sprague-Dawley rat (Rouse-Brouwer et al., 1984a,b). Phenobarbital has a half-life of $8 \mathrm{hr}$ in the rat, and the mean steady state plasma levels for the $60 \mathrm{mg} / \mathrm{kg}$ dose $(24.7 \pm 5.7 \mu \mathrm{g} / \mathrm{ml}$ in pilot studies; see Results) would decline to negligible levels during the $9 \mathrm{~d}$ interval, or 27 half-lives, between the last dose and the initiation of kindling stimulation.

\section{Results}

\section{Induction of lesions by intraventricular kainic acid}

As reported previously (Ben-Ari, 1985; Franck and Schwartzkroin, 1985; Franck et al., 1988), the lesions induced by intraventricular KA consisted of neuronal loss in the CA3 region and the hilus of the DG, which was accompanied by gliosis (Fig. $1 A-C$ ). Rats were included in the study only if neuronal loss and gliosis were observed in the CA3 region in at least two consecutive sections separated by $240 \mu \mathrm{m}$. This criterion ensured that KA was appropriately administered in all subjects of the various experimental groups. In addition, rats with implanted electrodes were included in the study only if the implanted electrodes were appropriately located in either the perforant path, or the DG. A total of 82 rats satisfied these criteria and were included in the study; 15 rats were excluded.

The most extensive neuronal loss was typically observed in the dorsal hippocampus adjacent to the injected ventricle, but the extent of the lesions in the ventral hippocampus was variable (see Figs. $1 C, 4 C, 5 C, 6 C, 7 C$ ).

\section{Effects of phenobarbital on seizures induced by $K A$}

Previous studies have reported that a single dose of phenobarbital $(60 \mathrm{mg} / \mathrm{kg}$, i.p.) was an effective anticonvulsant against acute KA-induced seizures for at least $24 \mathrm{hr}$ in rats (Feldblum and Ackermann, 1987). To assess the effects of phenobarbital against KA-induced seizures for longer intervals, spontaneous EEG was recorded from the DG of rats cotreated with phenobarbital administered immediately after completion of the KA injection and at daily intervals, according to methods described above

In four of four rats that were injected with $\mathrm{KA}$ and treated with phenobarbital at a dose of $30-40 \mathrm{mg} / \mathrm{kg}$, continuous electrographic seizure activity consisting of trains of irregular spike and spike-wave discharges was observed in the DG throughout the entire $8 \mathrm{hr}$ recording period after KA injection (see Fig. 2). During the $15 \mathrm{~min}$ period of recording at $24 \mathrm{hr}$ after KA injection, the electrographic discharges were no longer continuous, but diminished to frequent episodes of prolonged irregular spike and spike-wave activity, which were interrupted by runs of lowamplitude theta activity. During the $15 \mathrm{~min}$ period of recording on days 3-5 after $\mathrm{KA}$ injection, occasional runs of irregular spike and spike-wave activity were still observed, but were typically of shorter duration than on day 2 .

In six of six rats that received phenobarbital at a dose of 60 $\mathrm{mg} / \mathrm{kg}$, there was continuous electrographic seizure activity in the DG consisting of irregular spike and spike-wave discharges for the first $4 \mathrm{hr}$ of the initial $8 \mathrm{hr}$ recording period after injection

\begin{tabular}{|c|c|c|}
\hline & \multicolumn{2}{|l|}{ Phenobarbital } \\
\hline & $60 \mathrm{mg} / \mathrm{kg}$ & $30 \mathrm{mg} / \mathrm{kg}$ \\
\hline \multicolumn{3}{|l|}{ DG EEG } \\
\hline Day 1 & $\begin{array}{l}\text { Continuous seizures } \\
(0-4 \mathrm{hr}) \\
\text { Episodic seizures } \\
(4-8 \mathrm{hr})\end{array}$ & $\begin{array}{l}\text { Continuous seizures } \\
(0-8 \mathrm{hr})\end{array}$ \\
\hline Day 2 & $\begin{array}{l}\text { Rare seizures } \\
\text { Interictal spikes }\end{array}$ & Frequent seizures \\
\hline Day $3-4$ & No seizures & $\begin{array}{l}\text { Rare seizures } \\
\text { Interictal spikes }\end{array}$ \\
\hline $\begin{array}{l}\text { Phenobarbital } \\
\text { trough level } \\
(\mu \mathrm{g} / \mathrm{ml})\end{array}$ & $24.7 \pm 5.7$ & $1.98 \pm 0.3$ \\
\hline
\end{tabular}

of KA. In contrast to rats that received phenobarbital at doses of $30-40 \mathrm{mg} / \mathrm{kg}$, the continuous electrographic seizure activity diminished during the 4-8 $\mathrm{hr}$ after $\mathrm{KA}$ injection to episodic seizures consisting of irregular runs of spike and spike-wave activity, which were interrupted by runs of low-amplitude theta activity (see Fig. 2). During the 15 min period of recording at $24 \mathrm{hr}$ after KA injection in the $60 \mathrm{mg} / \mathrm{kg}$ group, there were only rare, brief runs of electrographic seizure activity, and occasional isolated interictal spikes. During the $15 \mathrm{~min}$ period of recording on days 3-5 after KA injection, there were no recorded episodes of electrographic seizure activity, and only rare interictal discharges.

The mean steady state trough plasma phenobarbital level for the group that received phenobarbital at a dose of $60 \mathrm{mg} / \mathrm{kg}$ was $24.7 \pm 5.7 \mu \mathrm{g} / \mathrm{ml}$, a steady state trough level of phenobarbital that was within a range associated with anticonvulsant effects in vivo, and with suppression of repetitive firing in vitro $(15-40 \mu \mathrm{g} / \mathrm{ml}$, or about $120 \mathrm{~mm}$ ) (MacDonald and McLean, 1986). The mean steady state trough plasma phenobarbital level for the group that received phenobarbital at a dose of 30-40 $\mathrm{mg} / \mathrm{kg}$ was $1.98 \pm 0.26 \mu \mathrm{g} / \mathrm{ml}$. Rats treated with phenobarbital at a dose of $60 \mathrm{mg} / \mathrm{kg}$ were initially sedated for 4-6 d, and appeared lethargic throughout the 2 week period of observation. The results of recording from the DG are summarized in Table 1 .

\section{Effects of phenobarbital on neuronal degeneration after $K A$}

The Fink-Heimer method was employed to assess neuronal and terminal degeneration in a separate group of rats at $72 \mathrm{hr}$ after intraventricular KA followed by phenobarbital $(60 \mathrm{mg} / \mathrm{kg}$ daily for $3 \mathrm{~d}$ ), and was compared with a group that received only intraventricular KA. In agreement with previous reports (Nadler and Cuthbertson, 1980; Nadler et al., 1980a), there was evidence of extensive neuronal degeneration manifested by dark-stained, pyknotic pyramidal neurons in $\mathrm{CA} 3, \mathrm{CA} 1$, and the hilus of the DG in five of five rats that received only KA (Fig. $3 B, E, F, H$ ). A laminar band of degenerating terminals and axons indicated by fine dark granules was observed in the supragranular and inner molecular layer of the $D G$ in a distribution that included the termination of the commissural-associational pathway from degenerating neurons in the hilus (Fig. $3 H$, arrows).

The pattern of degeneration in rats that were cotreated with $\mathrm{KA}$ and phenobarbital $(60 \mathrm{mg} / \mathrm{kg}$ for $3 \mathrm{~d}$ ) was different than in rats that received only $\mathrm{KA}$. Although neuronal degeneration was 

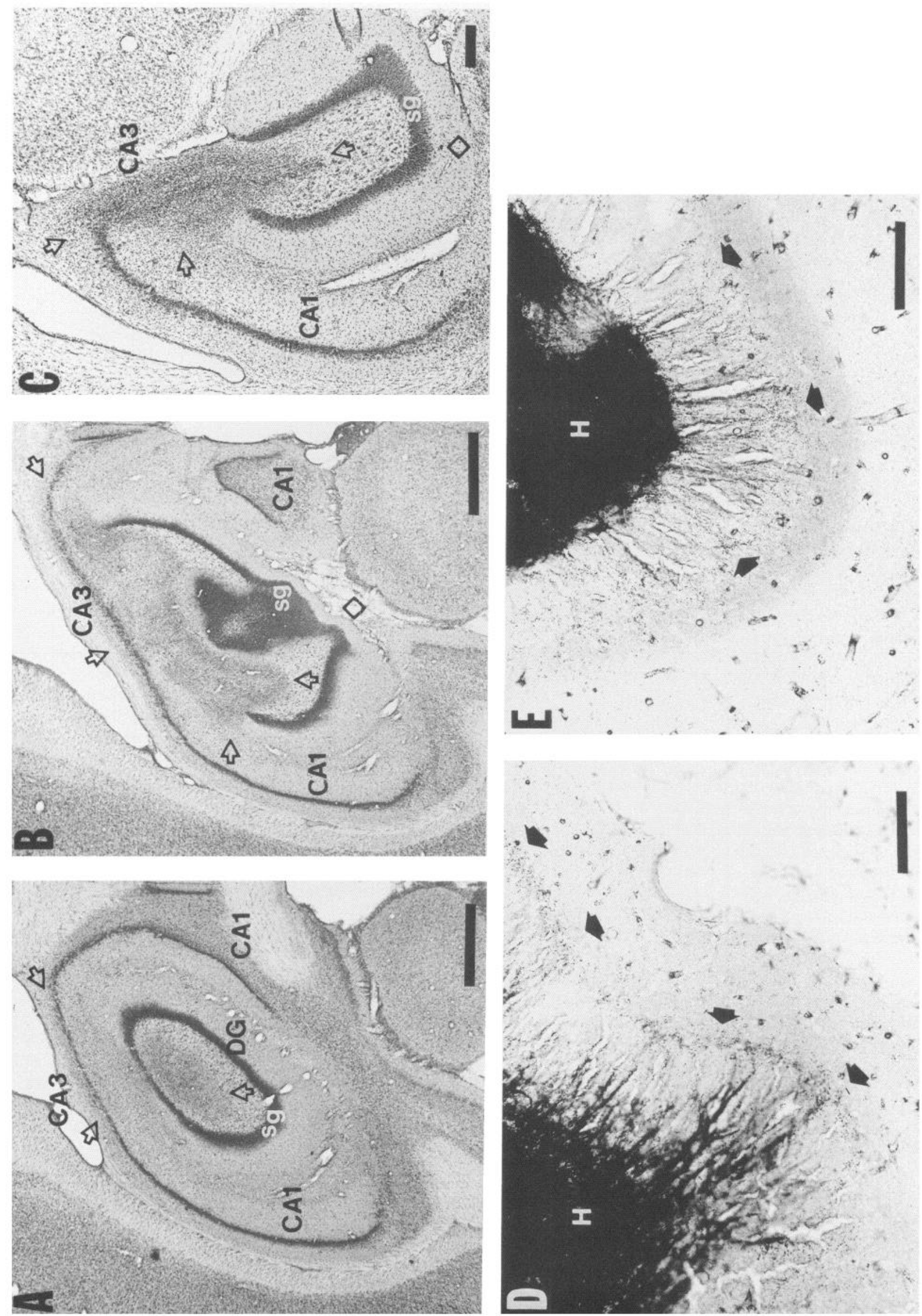


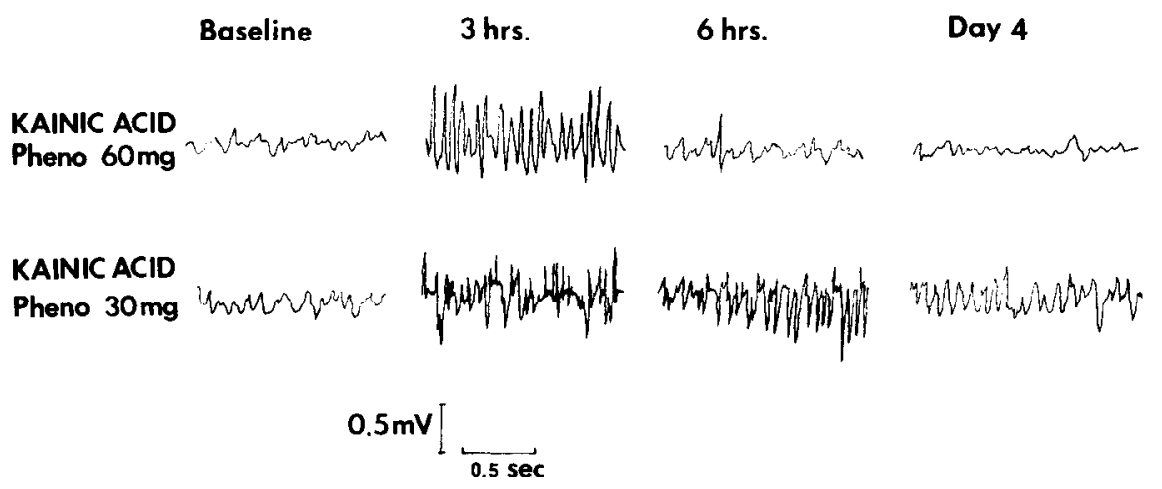

Figure 2. The effects of phenobarbital treatment on spontaneous EEG activity recorded from the DG of rats that received intraventricular KA coadministered with phenobarbital. Representative recordings from the baseline period just prior to administration of $\mathrm{KA}$, at 3 and $6 \mathrm{hr}$ after administration of KA, and $4 \mathrm{~d}$ later. Phenobarbital was administered in doses of either $30 \mathrm{mg} /$ $\mathrm{kg}$ or $60 \mathrm{mg} / \mathrm{kg}$. Polygraph records of the EEG were retraced for clarity. consistently observed in CA3 (Fig. $34, C$ ) and in CA1 (Fig. $3 D$ ), there was no evidence of degeneration in the supragranular layer of the dentate gyrus in seven of seven rats cotreated with phenobarbital (Fig. $3 G$ ). In comparison to the extensive neuronal degeneration in the hilus of the DG in rats treated only with $\mathrm{KA}$, degenerating neurons were rarely observed in this area in the phenobarbital-treated group.

\section{Effects of phenobarbital on mossy fiber sprouting and synaptic reorganization}

The supragranular layer of the DG in the normal rat is not innervated by mossy fibers (Amaral, 1979; Claiborne et al., 1986). In normal rats examined with Timm histochemistry, Timm granules that correspond to synaptic terminals of mossy fibers are densely packed in the hilus of the DG, but are usually sparse or absent in the supragranular layer, except at the most temporal pole of the dentate gyrus (Cavazos et al., 1992).

In agreement with previous studies (Nadler et al., 1980b; Laurberg and Zimmer, 1981; Ben-Ari, 1985), Timm histochemistry performed in 11 rats at 2 weeks after intraventricular administration of $\mathrm{KA}$ alone demonstrated Timm granules in a patchy distribution in the supragranular layer of the DG (Fig. $1 D, E)$. The Timm granules in this region are evidence of sprouting and synaptic reorganization of the mossy fiber pathway (Nadler et al., 1980b; Laurberg and Zimmer, 1981).

In 10 of $11 \mathrm{KA}$-treated rats with comparable lesions of CA3 that were cotreated with phenobarbital $(60 \mathrm{mg} / \mathrm{kg}$ once daily for 2 weeks), Timm granules were markedly reduced in the supragranular layer (compare Fig. $1 D, E$ with Fig. $4 D, E$ ). Large lesions were observed in CA3 in rats cotreated with phenobarbital (see Fig. $4 A-C$ ), but the Timm granules in the supragranular region in this group were quite sparse, and resembled the pattern observed in normal rats.

To assess more quantitatively the effect of cotreatment with phenobarbital on mossy fiber synaptic reorganization, the distribution of Timm granules in the supragranular layer was evaluated by the scoring techniques described in Materials and Methods. The Timm scores confirmed that treatment with phenobarbital $(60 \mathrm{mg} / \mathrm{kg}$ ) for $14 \mathrm{~d}$ after $\mathrm{KA}$ administration re- duced the extent of mossy fiber synaptic reorganization (mean score of $1.20 \pm 0.24$ in the treated group vs. $2.30 \pm 0.25$ in the group that received only KA, $p<0.01$; see Table 2 ).

The effect of phenobarbital treatment on Timm granules was dose dependent. In four of four rats from the group that received $\mathrm{KA}$ and phenobarbital at doses of $30-40 \mathrm{mg} / \mathrm{kg}$ once daily for $14 \mathrm{~d}$, the pattern of Timm granules in the supragranular layer was not significantly different than in rats that received only KA (see Table 2, and compare Fig. $1 D, E$ with Fig. $5 D, E$ ).

It was of interest to determine the time course of action of phenobarbital on mossy fiber sprouting and synaptic reorganization after administration of KA. In nine of nine rats that received intraventricular $\mathrm{KA}$ and phenobarbital $60 \mathrm{mg} / \mathrm{kg}$ during days 1-5 after injection of the KA, Timm granules were markedly reduced in the supragranular layer compared to the rats that received only $\mathrm{KA}$ (see Table 2, and compare Fig. 6D, $E$ with Fig. $1 D, E$ ). This effect was quite specific to days $1-5$ after $\mathrm{KA}$ administration, as five of five rats that received phenobarbital during days 9-14 demonstrated patterns of Timm granules in the supragranular layer that did not differ significantly from rats that received only $\mathrm{KA}$ (see Table 2, and compare Fig. $1 D, E$ with Fig. $7 D, E$, and Fig. $6 D, E$ with Fig. $7 D, E$ ). Treatment with phenobarbital $(60 \mathrm{mg} / \mathrm{kg}$ ) for $1 \mathrm{~d}$ after KA did not reduce mossy fiber synaptic reorganization in the supragranular layer.

\section{Effects of brief phenobarbital treatment on development of kindling}

To determine the effect of brief treatment with phenobarbital on the development of kindling, rats with a perforant path electrode were cotreated with intraventricular KA and phenobarbital ( $60 \mathrm{mg} / \mathrm{kg}$ daily for $5 \mathrm{~d}$ ). Kindling stimulation was delivered according to standard methods beginning 2 weeks after intraventricular injection of KA.

Rats that received phenobarbital at a dose of $60 \mathrm{mg} / \mathrm{kg}$ for 5 $\mathrm{d}$ after intraventricular KA administration developed generalized tonic clonic seizures (class $\mathrm{V}$ ) after 15.7 $\pm 1.9 \mathrm{ADs}$, a rate that was not distinguishable from normal unlesioned controls that did not receive phenobarbital ( $15.5 \pm 1.0$ ADs). Rats that received perforant path stimulation 2 weeks after intraventric-

Figure 1. Hippocampal damage and synaptic reorganization induced by KA. A-C, Cresyl-stained horizontal sections of hippocampus and DG of a rat that received intraventricular KA. There is neuronal loss and gliosis that involves CA3 and the hilus of the dentate gyrus in the dorsal hippocampus $(A, B)$. The lesion extends into $C A 3_{b, c}$ in the more ventral section in $C$. Open arrows indicate the borders of the observable lesion. $D$, Adjacent horizontal Timm-stained section from the location indicated by the diamond in $B$ demonstrates a dense laminar band of Timm granules in the supragranular region that correspond to labeled synaptic terminals of the mossy fiber pathway (solid arrows). E, A similar section obtained from the crest of the DG indicated by the diamond in $C$ also demonstrates Timm granules in the supragranular region (solid arrows). Abbreviations: $H$, hilus of the DG; $s g$, stratum granulosum. Scale bars: $A$ and $B, 1000 \mu \mathrm{m} ; C, 200 \mu \mathrm{m} ; D$ and $E, 100 \mu \mathrm{m}$. 
Table 2. Timm scores

\begin{tabular}{llll} 
& $\begin{array}{l}\text { Treatment } \\
\text { duration } \\
\text { Group }\end{array}$ & $\begin{array}{l}\text { Timm scorc } \\
\text { (mean } \pm \text { SEM) }\end{array}$ & $n$ \\
\hline $\mathrm{KA}$ & - & $2.30 \pm 0.25$ & 11 \\
$\mathrm{KA}, \mathrm{Pb} 60 \mathrm{mg} / \mathrm{kg}$ & $0-14$ & $1.20 \pm 0.24^{a}$ & $11^{d}$ \\
$\mathrm{KA}, \mathrm{Pb} 30-40 \mathrm{mg} / \mathrm{kg}$ & $0-14$ & $1.74 \pm 0.50^{b}$ & $4^{d}$ \\
$\mathrm{KA}, \mathrm{Pb} 60 \mathrm{mg} / \mathrm{kg}$ & $1-5$ & $1.64 \pm 0.23^{c}$ & $9^{e}$ \\
$\mathrm{KA}, \mathrm{Pb} 60 \mathrm{mg} / \mathrm{kg}$ & $9-14$ & $2.46 \pm 0.36$ & 5 \\
$\mathrm{KA}, \mathrm{Pb} 60 \mathrm{mg} / \mathrm{kg}$ & 1 & $2.60 \pm 0.48$ & 2 \\
\hline
\end{tabular}

$\mathrm{Pb}$, phenobarbital.

${ }^{a}$ Versus KA, $p<0.01$, two-tailed $t$ test.

${ }^{b}$ Versus KA, not significant.

c Versus KA, $p=0.075$, two-tailed $t$ test.

${ }^{a}$ Rats with recording electrodes in the DG were included in these groups.

${ }^{\circ}$ Kindled rats were not included in this group.

ular KA that induced a lesion in CA3 developed class V seizures more rapidly than normal rats without lesions $(10.5 \pm 0.8$ ADs vs. $15.5 \pm 1.0$ ADs, $p<0.001$; see Table 3, Fig. 8). Thus, brief treatment with phenobarbital $(60 \mathrm{mg} / \mathrm{kg}$ for $5 \mathrm{~d}$ ) abolished the increased susceptibility to kindling associated with hippocampal lesions induced by $\mathrm{KA}$.

The effect of phenobarbital on kindling was also dose dependent. Rats that received phenobarbital at a dose of $30 \mathrm{mg} / \mathrm{kg}$ for $5 \mathrm{~d}$ after intraventricular KA developed class $\mathrm{V}$ seizures after $11.4 \pm 2.6 \mathrm{ADs}$, a rate that was not distinguishable from KAlesioned controls (10.5 \pm 0.8 ADs).

\section{Discussion}

In this series of in vivo experiments, brief treatment with phenobarbital suppressed acute KA-induced seizure activity, pre- vented neuronal degeneration in the supragranular layer of the DG, reduced mossy fiber synaptic reorganization, and abolished the long-lasting increased susceptibility to kindling associated with hippocampal lesions. This discussion will address the following major points: (1) pharmacological issues in the assessment of the effect of phenobarbital on functional and structural alterations induced by KA in hippocampal circuitry, (2) evidence that modulation of KA-induced seizures by anticonvulsant action of phenobarbital altered specific patterns of neural degeneration and synaptic reorganization in the dentate gyrus, and (3) the role of seizures and associated reorganization of circuitry in the DG in the development of long-lasting increased susceptibility to kindling after administration of $\mathrm{K} \Lambda$.

\section{Assessment of the effects of phenobarbital on seizures, neuronal degeneration, and reorganization of hippocampal circuitry after $K A$}

Pharmacokinetics of phenobarbital in the rat. Several aspects of the pharmacokinetics of phenobarbital in Sprague-Dawley rats were exploited in the design of these experiments. Repeated administration of phenobarbital $(60 \mathrm{mg} / \mathrm{kg}$, i.p. or s.c., once daily) resulted in steady state trough phenobarbital levels that have been associated with anticonvulsant effects both in vivo and in vitro (MacDonald and McLean, 1988). As trough levels represent the lowest plasma concentration of phenobarbital prior to the next dose interval, it can be concluded that the steady state plasma levels achieved by the once-daily dose of $60 \mathrm{mg} /$ $\mathrm{kg}$ were in excess of levels that would be expected to suppress seizure activity during the $24 \mathrm{hr}$ interval between doses. This prediction was confirmed by recordings from the DG on days 1-5 after $\mathrm{KA}$ injection in rats that received phenobarbital at doses of $60 \mathrm{mg} / \mathrm{kg}$.

Anticonvulsant effects of phenobarbital against $K A$-induced

Figure 3. Effect of phenobarbital treatment on KA-induced degeneration in the hippocampus and DG. $A, C, D$, and $G$ are horizontal sections of hippocampus and DG stained with the Fink-Heimer method from a rat that received intraventricular KA and phenobarbital (60 mg/kg once daily). $B, E, F$, and $H$ are from a rat that received only KA. $A$ and $B$, In the CA 3 a region of the phenobarbital-treated $(A)$ and untreated $(B)$ rats, there was extensive neuronal degeneration indicated by numerous dark-stained, pyknotic cell bodies. The punctate dark-stained granules in the stratum oriens and stratum radiatum in $B$ are degenerating synaptic terminals. The lucent band adjacent to the stratum pyramidale corresponds to the terminal field of the mossy fibers arising from granule cells in the DG, which are relatively resistant to the neurotoxic effects of KA. $C$, Higher magnification of the region in $C A 3_{a}$ indicated by the arrow in $A$ from a rat treated with phenobarbital demonstrates numerous degenerating pyknotic cell bodies, and degenerating synaptic terminals in the stratum oriens and stratum radiatum $C$. $D$. In the CAl region of the phenobarbital-treated rat, there were numerous degenerating, dark, pyknotic cell bodies. $E$. Higher magnification of the region of $C A 3_{a}$ indicated by the arrow in $B$ from a rat that received only KA demonstrates numerous degenerating pyknotic cell bodies, and degenerating fibers and synaptic terminals in the stratum oriens and stratum radiatum. $F$, There was extensive neuronal degeneration in CAl of the untreated rat that extended into the CAl-subiculum transitional zone. $G$. Despite extensive degeneration in CA3 and CAl of the rat treated with phenobarbital $(A, C, D)$, a horizontal section of the DG from this rat reveals no evidence of degeneration in the inner molecular layer (arrows), and only very rare degenerating neurons in the hilus. $H$, A horizontal section of the DG from the rat that received only KA demonstrates numerous degenerating neurons in the hilus, and a dense band of degenerating terminals in the inner molecular layer (arrows). Scale bars: $A, B, D$, and $F, 100 \mu \mathrm{m} ; C$ and $E, 25 \mu \mathrm{m} ; G$ and $H, 50 \mu \mathrm{m}$.

Figure 4. Effects of phenobarbital $(60 \mathrm{mg} / \mathrm{kg}$ once daily for $14 \mathrm{~d})$ on hippocampal lesions and synaptic reorganization induced by $\mathrm{KA}$. $A-C$, Cresylstained horizontal sections of hippocampus from a rat that received intraventricular KA coadministered with phenobarbital (60 mg $/ \mathrm{kg}$, i.p.) once daily for $14 \mathrm{~d}$. There is neuronal loss and gliosis in CA3 in the dorsal hippocampus $(A, B)$ and that extends into more ventral sections of CA $3_{\mathrm{a}}$ in $C$. Open arrows indicate the borders of the lesion. The electrode track for recording from the DG is apparent in $A$ and $B$. $D$, In an adjacent horizontal Timm-stained section from the location indicated by the diamond in $A$, Timm granules were only rarely observed, and did not form patches of confluent granules or laminar bands in the supragranular region (open arrows), as was commonly observed in rats that were not treated with phenobarbital (compare to Fig. $1 D$ ). E. Timm granules were not apparent in the supragranular region in a similar section obtained from the crest of the DG indicated by the diamond in $C . H$, hilus of the DG. Scale bars are as in Figure 1.

Figure 5. Effects of phenobarbital ( $30 \mathrm{mg} / \mathrm{kg}$ once daily for $14 \mathrm{~d}$ ) on hippocampal lesions and synaptic reorganization induced by KA. A-C, Cresylstained horizontal sections of hippocampus from a rat that received intraventricular KA coadministered with phenobarbital (30 mg/kg, i.p.) once daily for $14 \mathrm{~d}$. There is neuronal loss and gliosis in CA3 $(A, B)$. Open arrows indicate the borders of the lesion, which does not extend into more ventral hippocampus in $C$. The electrode track for recording from the DG is apparent in the hilus and stratum granulosum in $A$ and $B$. $D$, Adjacent horizontal Timm-stained sections from the location indicated by the diamond in $B$ demonstrate a laminar band of Timm granules in the supragranular region (solid arrows). E, A similar section obtained from near the crest of the DG indicated by the diamond in $C$ also demonstrates confluent patches of Timm granules in the supragranular region (solid arrows). The effectiveness of phenobarbital doses of $60 \mathrm{mg} / \mathrm{kg}$ in reducing synaptic reorganization compared to $30 \mathrm{mg} / \mathrm{kg}$ doses is indicated by the minimal evidence for Timm granules in $4 D$ and $4 E$ versus Figure $5, D$ and $E$, despite the larger size of the lesion (compare Fig. $4 A-C$ with Fig. 5A-C). $H$, hilus of the DG. Scale bars are as in Figure 1. 
$A^{2}, z^{2}+2$

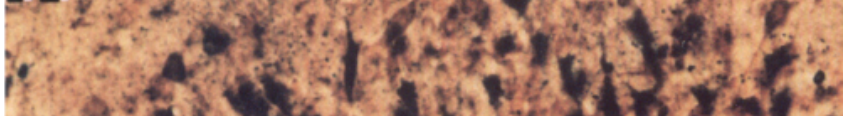

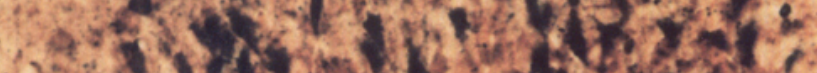

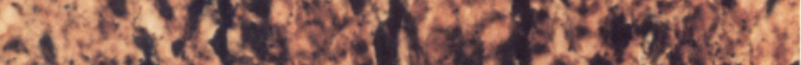

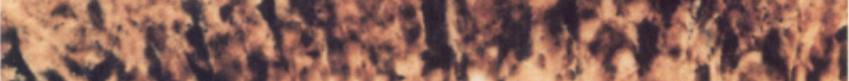
1.t.

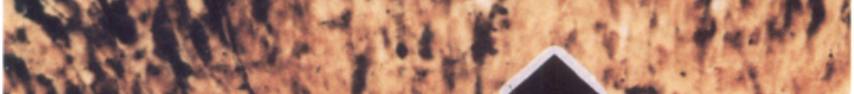

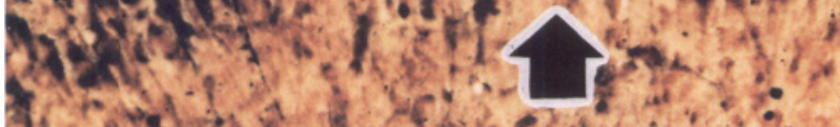

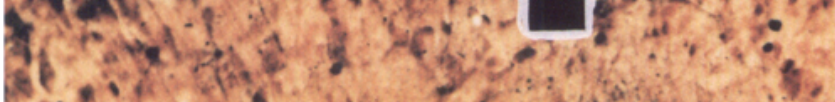
a. $20 x+26=$
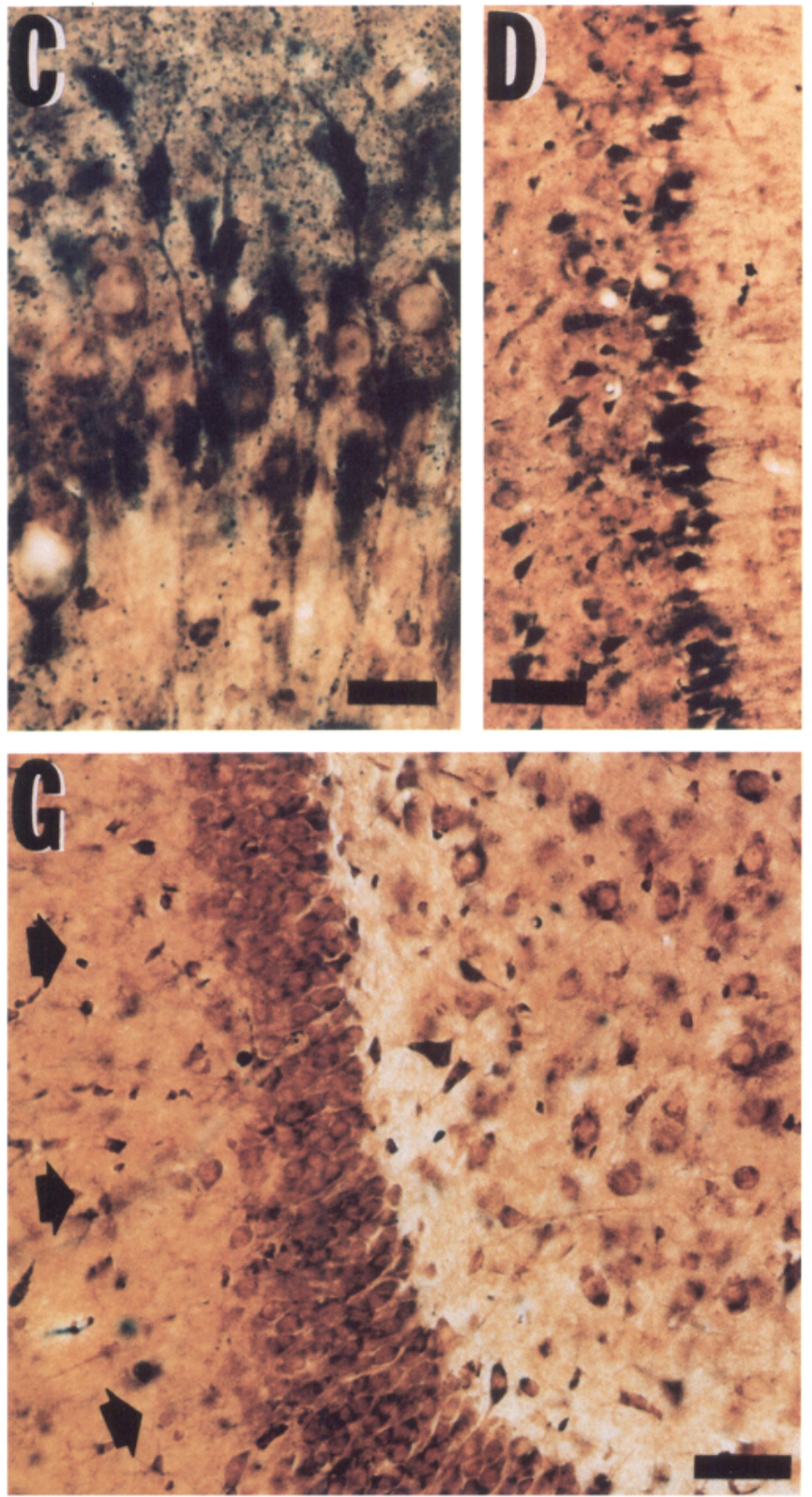
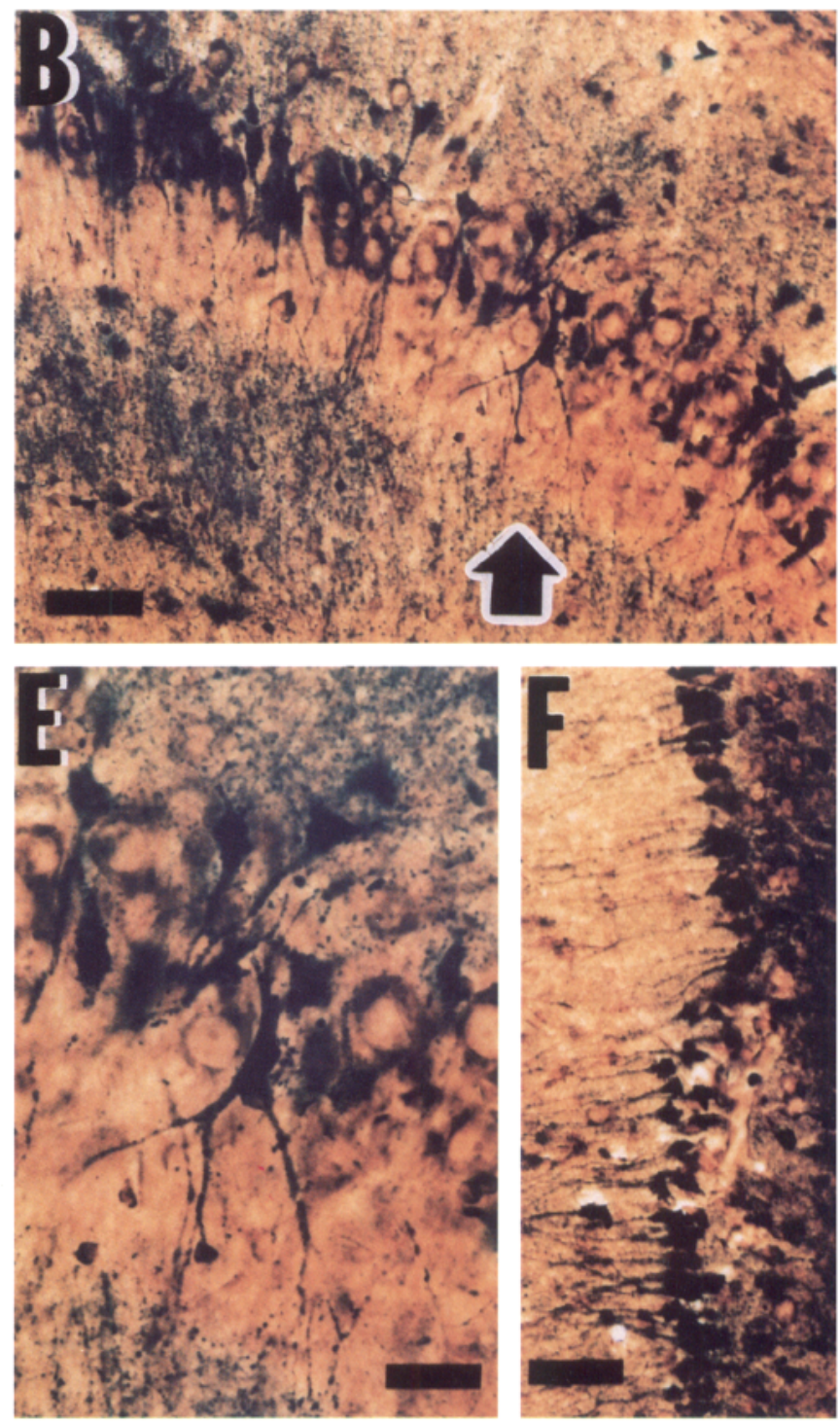

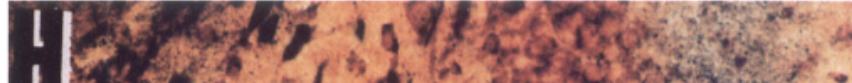

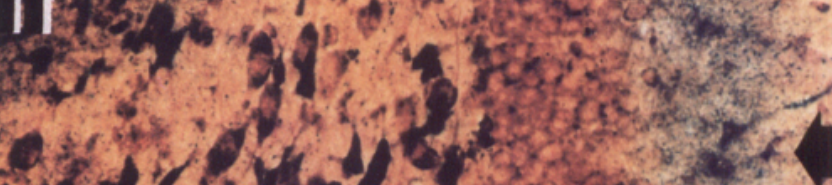

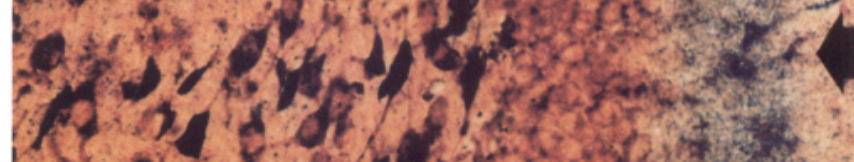

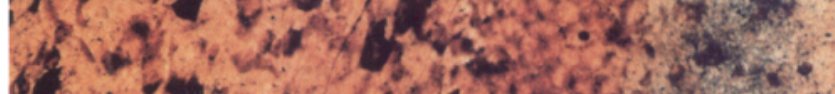

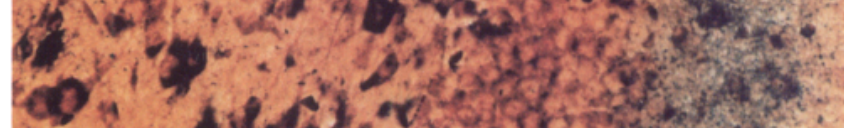

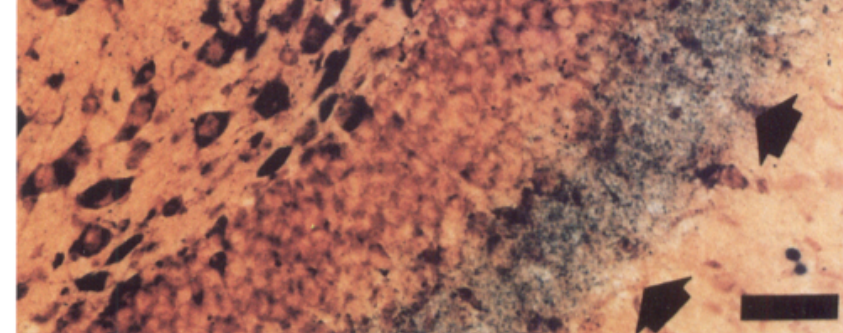



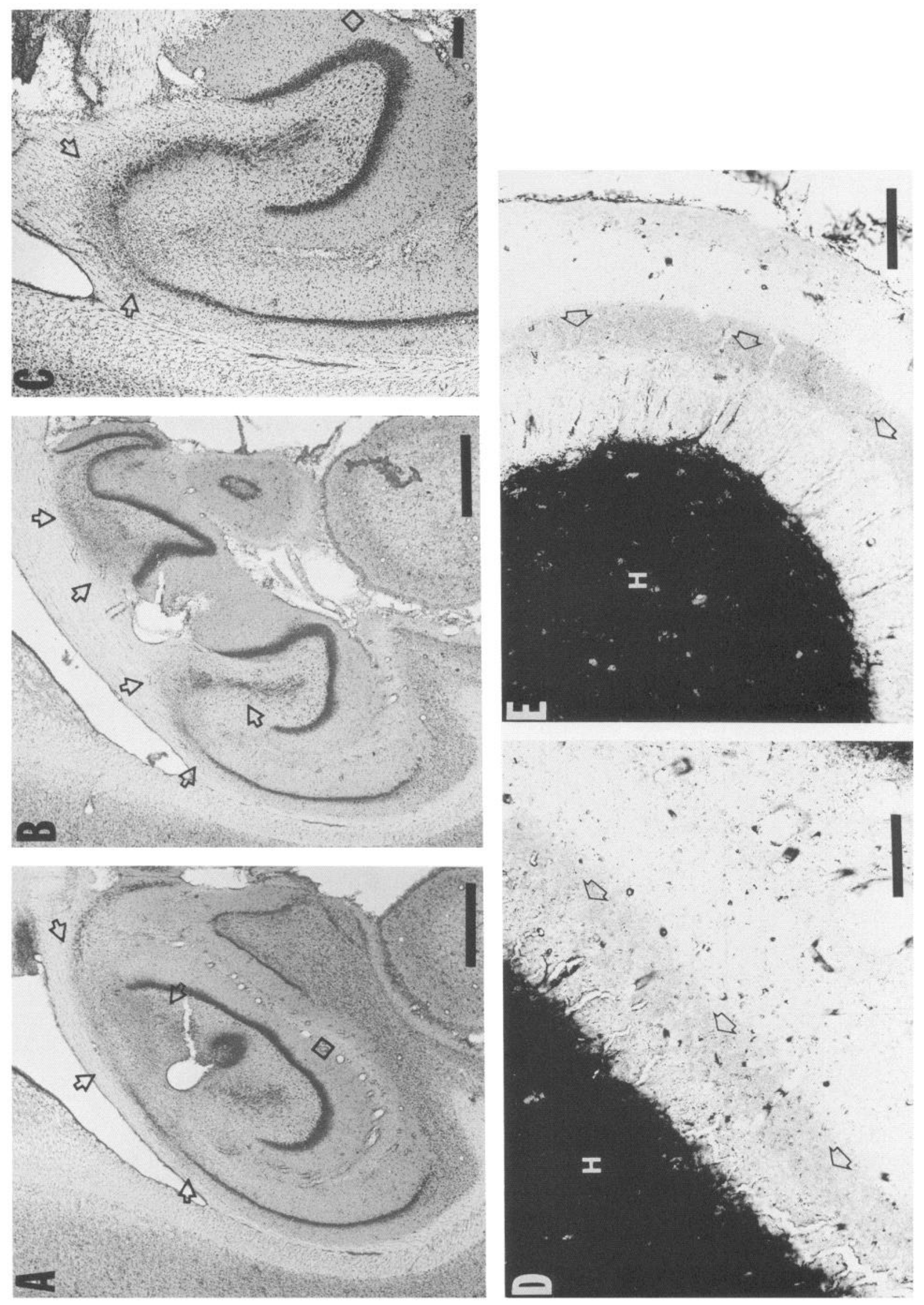

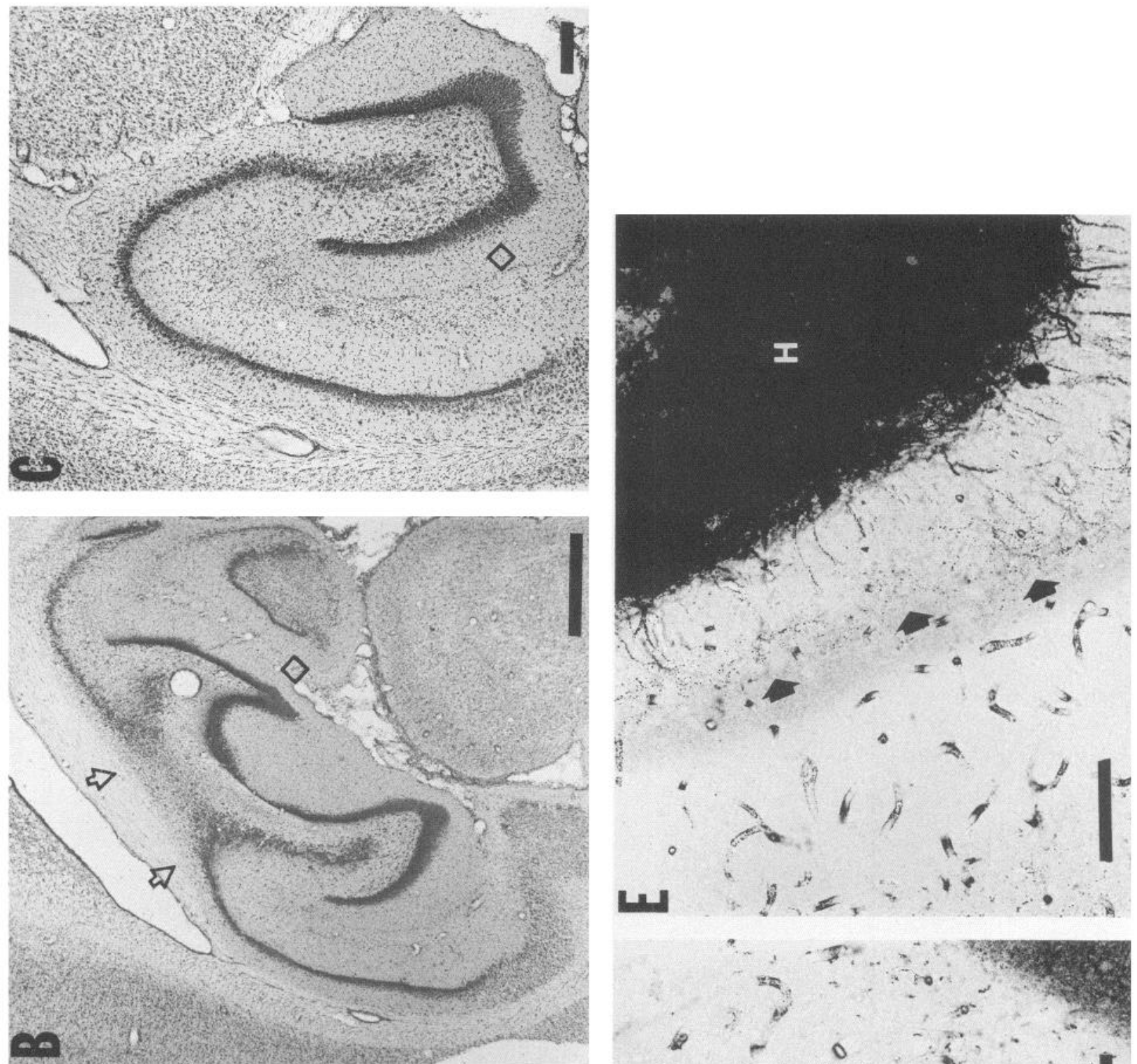

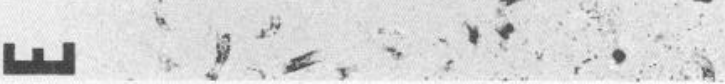
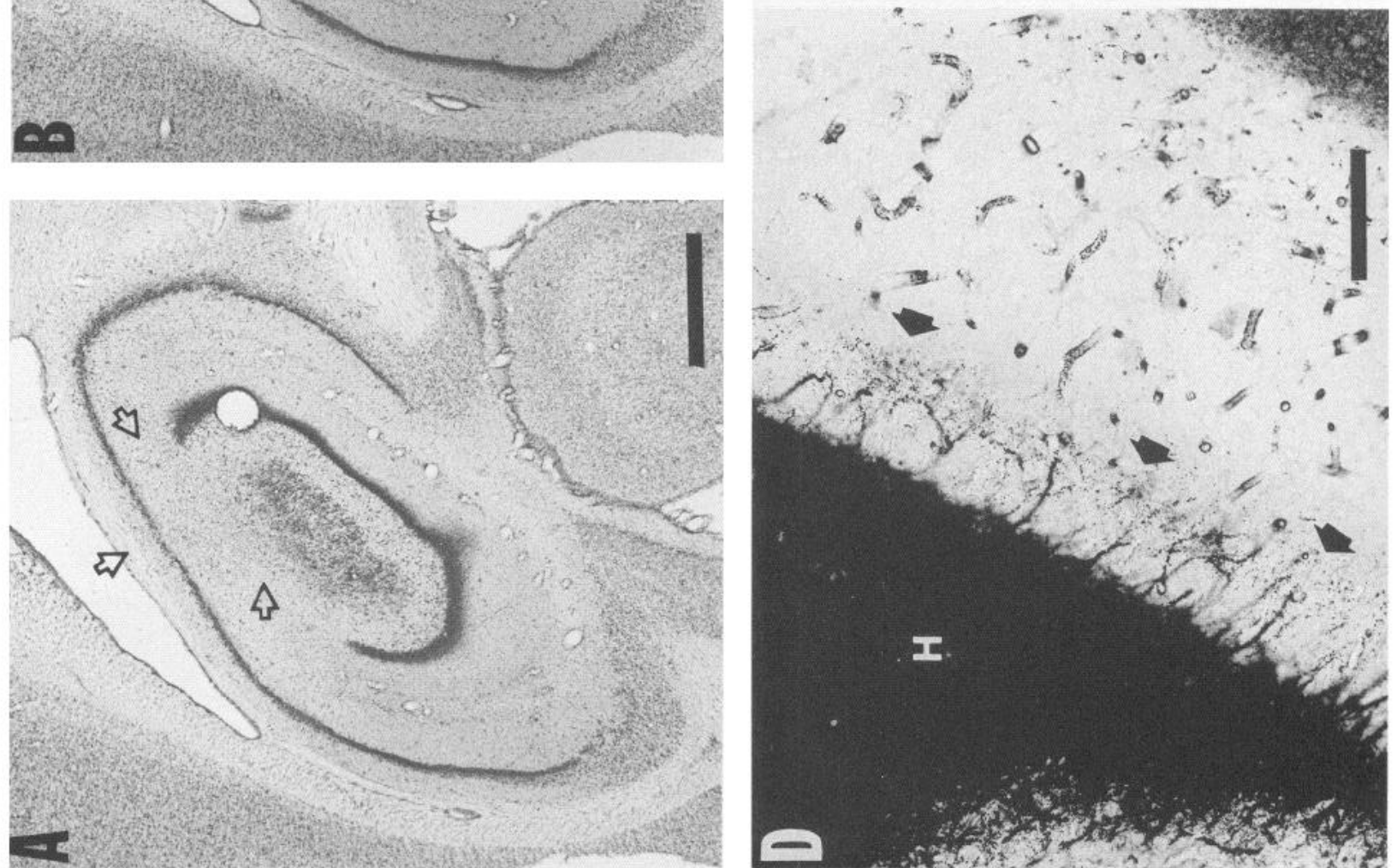

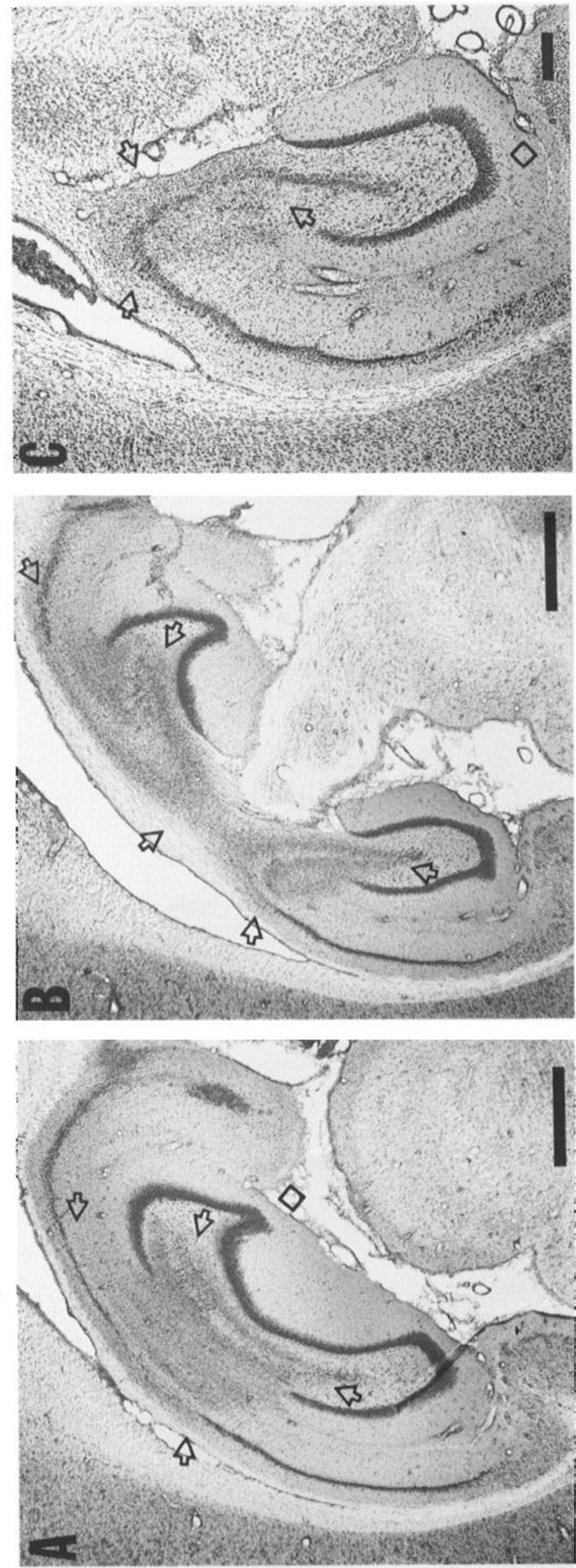

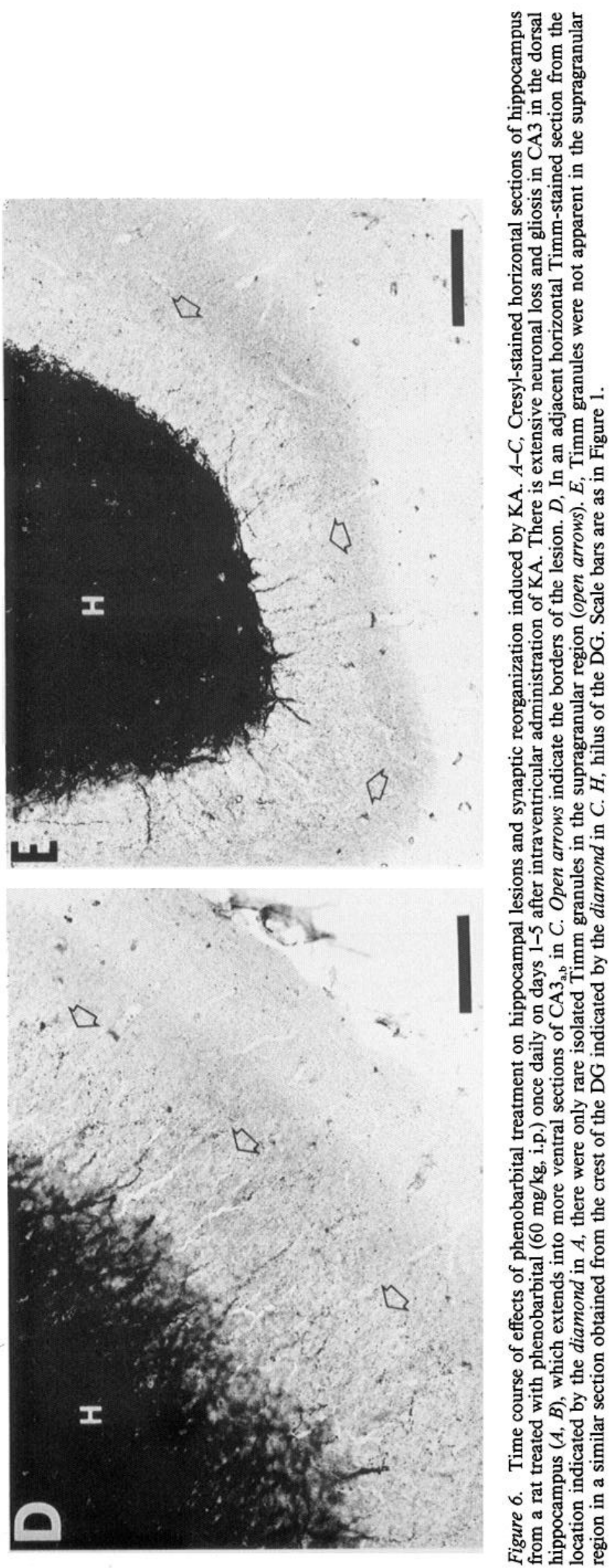

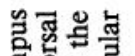

융

요요

a.․․요

远品

․․․․․․

.

舟

단.

응

절

응요

记

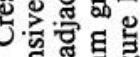

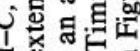

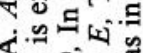

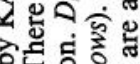

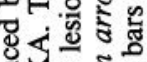

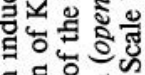

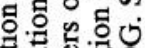

政

.

웡듀

늘

드의

क एँ

. व

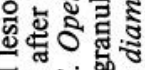

बำ

ㄴ.

守 $\mathrm{n}^{\circ} \mathrm{d}$

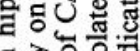

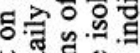

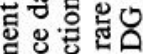

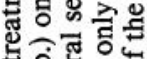

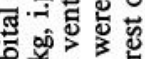

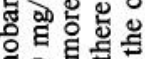

응을혀

o.

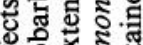

덩 경 웡

․ㅕㄴ용

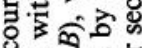

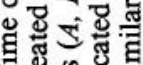

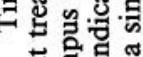

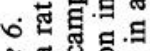

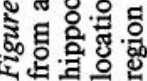



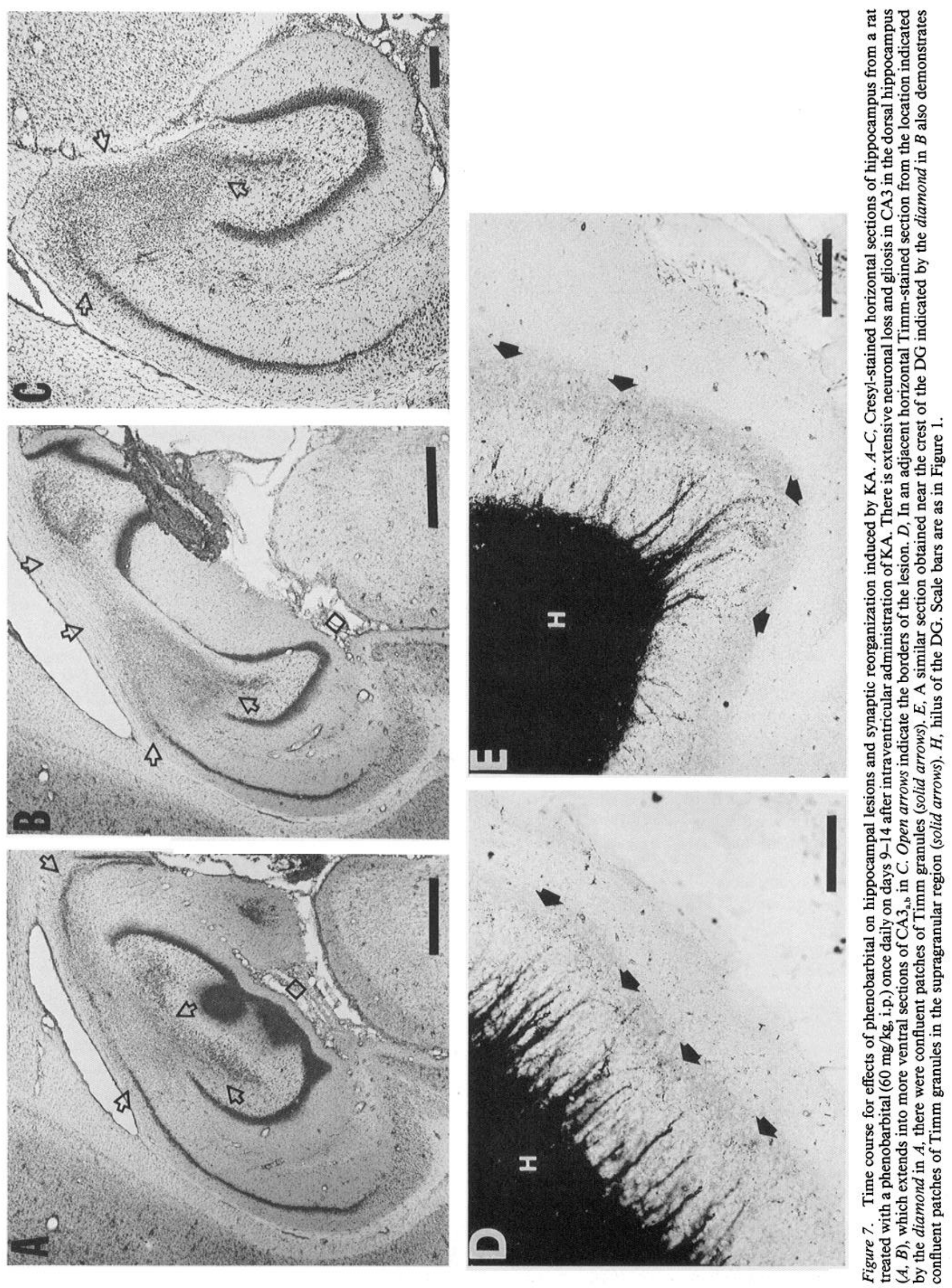

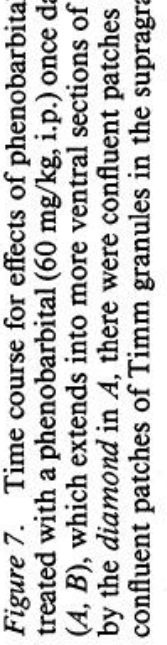


Table 3. Rate of kindling

\begin{tabular}{lrlll} 
& & \multicolumn{2}{l}{$\begin{array}{l}\text { ADs (to 1st } \\
\text { class V; mean }\end{array}$} & \multicolumn{2}{l}{ Stimulus intensity } \\
\cline { 4 - 5 } & $n$ & \pm SEM) & 1 st AD & Last AD \\
\hline $\mathrm{KA}$ & 26 & $10.8 \pm 0.9^{a}$ & $842 \pm 57$ & $513 \pm 63$ \\
Controls & 17 & $15.5 \pm 1.0$ & $870 \pm 58$ & $412 \pm 67$ \\
$\mathrm{KA}-\mathrm{Pb} \mathrm{60} \mathrm{mg/kg}$ & 7 & $15.7 \pm 1.9^{b}$ & $864 \pm 43$ & $686 \pm 107$ \\
$\mathrm{KA}-\mathrm{Pb} \mathrm{30} \mathrm{mg/kg}$ & 7 & $11.4 \pm 1.5^{c}$ & $814 \pm 86$ & $716 \pm 93$ \\
\hline
\end{tabular}

a Versus Controls, $p<0.001$

${ }^{b}$ Versus KA, $p<0.02$.

c Versus $\mathrm{KA}-\mathrm{Pb} 60 \mathrm{mg} / \mathrm{kg}, p<0.05$.

seizures. The first anticonvulsant effects of phenobarbital in doses of $60 \mathrm{mg} / \mathrm{kg}$ were noted at $4-8 \mathrm{hr}$ after initial administration. This onset of action probably reflected the gradual approach toward anticonvulsant levels that would be expected on the basis of the $8 \mathrm{hr}$ half-life of phenobarbital in Sprague-Dawley rats (Rouse-Brouwer et al., 1984a,b). Seizures were suppressed by 4 hr after KA injection, and recordings from the DG corresponding to trough levels on days 2-4 after KA administration revealed only rare interictal epileptic discharges. In contrast, phenobarbital treatment in doses of $30-40 \mathrm{mg} / \mathrm{kg}$ once daily, which resulted in a steady state trough level of $1.98 \pm 0.26 \mu \mathrm{g} / \mathrm{ml}$, failed to suppress epileptic activity during days $1-5$. Both theoretical pharmacokinetic considerations and EEG recordings were consistent with a direct anticonvulsant action of phcnobarbital on acute seizures induced by KA.

Dose-response of phenobarbital effects on degeneration and synaptic reorganization. Phenobarbital treatment with doses of $60 \mathrm{mg} / \mathrm{kg}$ once daily prevented degeneration in the inner molecular layer of the DG in rats that received KA. Sprouting and synaptic reorganization of the mossy fiber pathway in the inner molecular layer were also markedly reduced in rats treated with this dose, as indicated by the statistically significant reduction of Timm scores. In contrast, phenobarbital treatment with doses of $30-40 \mathrm{mg} / \mathrm{kg}$ once daily failed to suppress epileptic activity effectively in the DG during days $1-4$ after KA administration, and did not reduce mossy fiber synaptic reorganization. The similar dose-response relationships for phenobarbital action on seizures, degeneration, and mossy fiber synaptic reorganization suggested that the effects of phenobarbital were a consequence of suppression of the acute seizure activity.

Time course of phenobarbital effects on seizures, degeneration, and synaptic reorganization. Further support for this interpretation was provided by study of the time course of action of phenobarbital on mossy fiber sprouting and synaptic reorganization. Phenobarbital treatment with doses of $60 \mathrm{mg} / \mathrm{kg}$ once daily during days 1-5 after $\mathrm{KA}$ injection, an interval characterized by intense sustained seizure activity, also markedly reduced mossy fiber sprouting and synaptic reorganization. When seizures were untreated during days $1-5$ after $\mathrm{KA}$ injection and phenobarbital was administered at doses of $60 \mathrm{mg} / \mathrm{kg}$ once daily during days 9-14, the pattern of mossy fiber synaptic reorganization was comparable to rats that received only KA. This observation and the similar dose-response relationships for phenobarbital action on seizures, degeneration, and Timm scores support the interpretation that suppression of seizures during the $5 \mathrm{~d}$ after $\mathrm{KA}$ administration prevented neural degeneration and reduced synaptic reorganization in the DG.

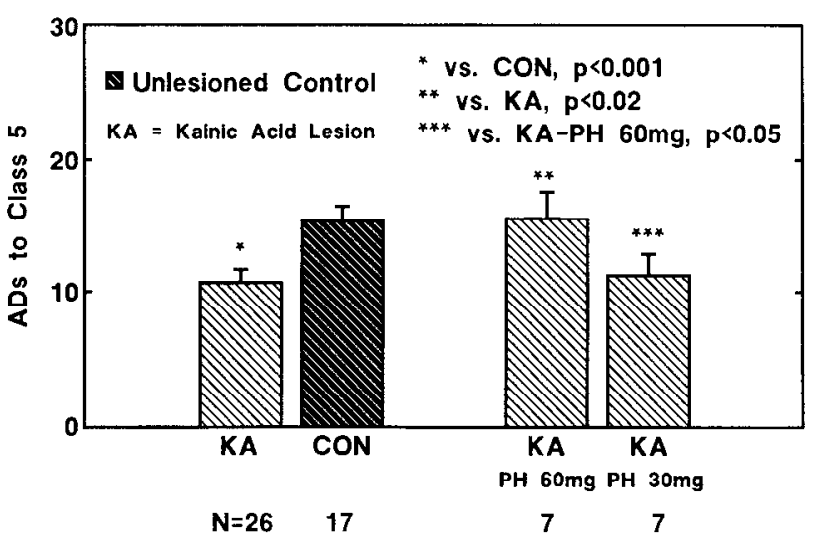

Figure 8. Effects of phenobarbital treatment on rate of kindling after induction of hippocampal lesions by KA. Rats treated with phenobarbital in a dose of $60 \mathrm{mg} / \mathrm{kg}$ once daily on days $1-5$ after intraventricular administration of KA developed class $\mathrm{V}$ seizures more slowly than rats that received only KA. Error bars are the SEM. The rate of development of kindling in rats treated with this dose of phenobarbital did not differ from normal unlesioned controls $(C O N)$. Rats treated with lower doses of phenobarbital $(30 \mathrm{mg} / \mathrm{kg}$ once daily for days $1-5)$ that were insufficient to suppress acute seizures, prevent degeneration, and reduce synaptic reorganization, developed class $\mathrm{V}$ seizures at a rate comparable to rats that received only $\mathrm{KA}$.

Acute seizures induced by kainic acid as a cause of specific patterns of neuronal damage, reactive sprouting, and synaptic reorganization

Neurons in the hilus of the DG are known to be specifically vulnerable to "excitotoxic" damage as a consequence of sustained seizures induced by KA (Ben-Ari et al., 1979; Nadler and Cuthbertson, 1980; Nadler et al., 1980a) and other experimental manipulations (Sloviter and Damiano, 1981; Sloviter, 1987). This study directly confirmed that polymorphic neurons in the hilus of the DG are specifically vulnerable to seizure-induced injury. Anticonvulsant treatment that protected against seizureinduced damage in the DG also reduced sprouting and synaptic reorganization of the mossy fiber pathway, but did not significantly protect pyramidal neurons in CA 3 and CA 1 from damage after KA administration. Other factors appear to play a more dominant role in the neuronal damage observed in CA3 and CAl in association with KA (Sater and Nadler, 1987; Ault et al., 1986; Gruenthal et al., 1986).

The results of this study demonstrated that the modifying effect of phenobarbital on neuronal damage and reactive sprouting after administration of KA was mediated by suppression of acute KA-induced seizures. Previous studies have demonstrated that drugs that enhance GABA-mediated inhibition can modify seizure-induced damage (Ben-Ari et al., 1979; Ylinen et al., 1991), and it is likely that the anticonvulsant action of phenobarbital in this study was at least partially caused by its enhancement of GABA-mediated inhibition. However, the present experiments were not sufficient to exclude the possibility that other molecular actions of phenobarbital in the doses employed in this study might also directly reduce neuronal vulnerability to injury.

\section{Seizure-induced alterations in hippocampal circuitry as a cause of increased susceptibility to kindling}

The results of this study identified days 1-5 aftcr KA administration as a critical period in the induction of long-lasting 
increased susceptibility to kindling. Rats treated with phenobarbital in doses that suppressed seizures in the DG during the 1-5 days after KA administration developed kindled seizures at rates that were comparable to normal control rats. In contrast, rats treated with doses insufficient to suppress seizures in the DG during the 1-5 $\mathrm{d}$ after $\mathrm{KA}$ administration developed kindled seizures at rates comparable to lesioned rats that received only KA.

These observations implicated KA-induced seizures and associated alterations in circuitry of the DG as a possible cause of increased susceptibility to kindling after KA. Results of other studies support the interpretation that cellular alterations in the DG may play an important role in the development of kindling. In contrast to hippocampal lesions, which induced mossy fiber synaptic reorganization and increased the rate of kindling (Sutula et al., 1987; Feldblum and Ackermann, 1987), destruction of granule cells in the DG markedly impairs the development of kindling (Dasheiff and McNamara, 1982; Frush et al., 1986; Sutula et al., 1986). These observations do not exclude the possibility that other neuronal populations also influence the development of kindling, but support the interpretation that specific cellular alterations in the $D G$ play an important role in the development of kindling, and are unlikely to be mere epiphenomena associated with critical changes in other regions.

The specific cellular and molecular alterations in the DG that are responsible for the increased susceptibility to development of kindled seizures were not identified in this study. The DG is the site of numerous molecular and cellular alterations induced during the development of kindling, including sprouting with synaptic reorganization (Sutula et al., 1988; Represa et al., 1989a), potentiation of synaptic efficacy and enhancement of NMDAmediated synaptic transmission (Mody et al., 1988), alterations in $\mathrm{Ca}^{2+}$ currents (Mody et al., 1990), changes in shape of the dendritic spines of granule cells (Geinisman et al., 1988, 1990), and alterations in the ionic composition of the extracellular environment (Wadman et al., 1985). In addition, kindling is also associated with complex alterations in a variety of neurotransmitter and neuromodulatory systems (McNamara, 1984; Stanton et al., 1989; Chen et al., 1990; Jarvie et al., 1990; Wu et al., 1990), second messenger systems (Akiyama et al., 1989; Bronstein et al., 1990), and glia (Hansen et al., 1990). These and other unrecognized cellular and molecular alterations in reorganized circuitry of the DG could individually or in combination play a role in the generation of epileptic activity. Although mossy fiber sprouting could increase recurrent excitation in pathways of the DG that normally lack recurrent excitatory circuits (Fricke and Prince, 1984; Cronin et al., 1992), efforts to characterize the role of synaptic reorganization and other specific cellular and molecular alterations in the generation of epileptic activity need to address the variety and complexity of potential mechanisms (Sloviter, 1992; Sutula et al., in press).

\section{Implications of pharmacological alteration of cellular responses to seizure-induced hippocampal injury}

The results of these experiments may have clinical importance. Hippocampal sclerosis, the most common lesion associated with human epilepsy, is characterized by hippocampal neuronal loss and mossy fiber synaptic reorganization. In this study, experimental hippocampal lesions with neuronal damage and synaptic reorganization that resembled many features of human hippocampal sclerosis (de Lanerolle et al., 1989; Represa et al., 1989b; Sutula et al., 1989; Houser et al., 1990; Babb et al., 1991) were accompanied by increased susceptibility to development of epilepsy by kindling. The increased susceptibility to kindling was completely abolished by brief treatment with phenobarbital, which protected against seizure-induced neurotoxic damage and reduced mossy fiber sprouting in the DG. Pharmacological interventions that reduce excitatory amino acid neurotoxicity after sporadic seizures or brain injury may prevent long-term cellular consequences of uncontrolled seizures such as neuronal death, axonal sprouting, and synaptic reorganization. Prevention of these long-lasting structural effects of uncontrolled seizures may protect against the development of medically refractory epilepsy, and favorably alter the prognosis and natural history of epileptic syndromes (Sutula, 1990).

Of more general significance, the observations of this study provided evidence that brief pharmacological intervention can modify cellular responses to injury and structural damage in the CNS, and alter the long-lasting functional effects of injury. Our observations were confined to the effects of phenobarbital on lesion-induced plasticity of the mossy fiber pathway in the dentate gyrus, but similar phenomena may occur in other pathways of the brain and with other pharmacological agents.

\section{References}

Akiyama K, Yamada N, Otsuki S (1989) Lasting increase in excitatory amino acid receptor-mediated polyphosphoinositide hydrolysis in the amygdala-pyriform cortex of amygdala-kindled rats. Brain Res 485: 95-101.

Amaral D (1979) Synaptic extensions from the mossy fibers of the fascia dentata. Anat Embryol 155:241-251.

Ault B, Gruenthal M, Armstrong D, Nadler JV (1986) Efficacy of baclofen and phenobarbital against the kainic acid limbic seizurebrain damage syndrome. J Pharmacol Exp Ther 239:612-617.

Babb T, Brown W (1987) Pathological findings in epilepsy. In: Surgical treatment of the epilepsies (Engel J, ed), pp 511-540. New York: Raven.

Babb TL, Kupfer WR, Pretorius JK, Crandall PH, Levesque MF (1991) Synaptic reorganization by mossy fibers in human epileptic fascia dentata. Neuroscience 42:351-363.

Ben-Ari Y (1985) Limbic seizure and brain damage produced by kainic acid: mechanisms and relevance to human temporal lobe epilepsy. Neuroscience 14:375-403.

Ben-Ari Y, Tremblay E, Ottersen O, Naquet R (1979) Evidence suggesting secondary epileptogenic lesions after kainic acid: pre-treatment with diazepam reduces distant but not local damage. Brain Res 165:362-365.

Bronstein JM, Farber DB, Micevych PE, Lasher R, Wasterlain CG (1990) Kindling induced changes in calmodulin kinase-II immunoreactivity. Brain Res 524:49-53.

Cavazos J, Golarai G, Sutula T (1991) Mossy fiber synaptic reorganization induced by kindling: time course of development, progression, and permanence. J Neurosci 11:2795-2803.

Cavazos JE, Sutula TP (1990) Progressive neuronal loss induced by kindling: a possible mechanism for mossy fiber synaptic reorganization and hippocampal sclerosis. Brain Res 527:1-6.

Cavazos JE, Sutula TP (1991) Pyramidal cell loss in CA1 and CA2 induced by kindling: evidence that repeated seizures may cause hippocampal sclerosis. Epilepsia 32[Suppl 3]:66.

Cavazos JE, Golarai G, Sutula TP (1992) Septotemporal variation of the supragranular projection of the mossy fiber pathway in the dentate gyrus of normal and kindled rats. Hippocampus, in press.

Chen LS, Weingart JB, McNamara J (1990) Biochemical and radiohistochemical analyses of alpha-2 adrenergic receptors in the kindling model of epilepsy. J Pharmacol Exp Ther 253:1272-1277.

Claiborne BJ, Amaral DG, Cowan WM (1986) A light and electron microscopic study of the mossy fibers of the rat dentate gyrus. J Comp Neurol 246:435-458.

Cotman CW, Nieto-Sampedro M, Harris EW (1981) Synapse replacement in the nervous system of adult vertebrates. Physiol Rev 61:682784.

Cronin J, Dudek E (1988) Chronic seizures and collateral sprouting 
of dentate mossy fibers after kainic acid treatment in rats. Brain Res 474:181-184.

Cronin J, Obenaus A, Houser CR, Dudek FE (1992) Electrophysiology of dentate granule cells after kainate-induced synaptic reorganization of the mossy fibers. Brain Res 573:305-310.

Danscher G (1981) Histochemical demonstration of heavy metals: a revised version of the silver sulphide method suitable for both light and electron microscopy. Histochemistry 71:1-16.

Danscher G, Howell G, Perez-Clausell J, Hertel N (1985) The dithizone, Timm's sulphide silver and the selenium methods demonstrate a chelatable pool of zinc in CNS. Histochemistry 83:419-422.

Dasheiff RM, McNamara JO (1982) Intradentate colchicine retards the development of amygdala kindling. Ann Neurol 11:347-352.

de Lanerolle N, Kim J, Robbins R, Spencer D (1989) Hippocampal interneuron loss and plasticity in human temporal lobe epilepsy. Brain Res 495:387-395.

de Olmos JS, Ebbesson SOE, Heimer L (1981) Silver methods for the impregnation of degenerating axoplasm. In: Neuroanatomical tract tracing methods (Heimer L, RoBards MJ, eds), pp 117-170. New York: Plenum

Feldblum S, Ackermann R (1987) Increased susceptibility to hippocampal and amygdala kindling following intrahippocampal kainic acid. Exp Neurol 97:255-269.

Fink RP, Heimer LM (1967) Two methods for selective silver impregnation of degenerating axons and their synaptic endings in the central nervous system. Brain Res 4:369-374.

Franck J, Schwartzkroin P (1985) Do kainate-lesioned hippocampi become epileptogenic? Brain Res 329:309-313.

Franck JE, Kunkel DD, Baskin DG, Schwartzkroin P (1988) Inhibition in kainate-lesioned hyperexcitable hippocampi: physiologic, autoradiographic, and immunocytochemical observations. J Neurosci 8: 1991-2002.

Frederickson CJ, Klitenick MA, Manton WI, Kirkpatrick JB (1983) Cytoarchitectonic distribution of zinc in the hippocampus of man and the rat. Brain Res 273:335-339.

Fricke RA, Prince DA (1984) Electrophysiology of dentate granule cells. J Neurophysiol 51:195-209.

Frush DP, Giacchino J, McNamara JO (1986) Evidence implicating dentate granule cells in development of entorhinal kindling. Exp Neurol 92:92-101.

Geinisman Y, Morrell F, de Toledo-Morrell L (1988) Remodeling of synaptic architecture during hippocampal "kindling." Proc Natl Acad Sci USA 85:3260-3264.

Geinisman Y, Morrell F, de Toledo-Morrell L (1990) Increase in the relative proportion of perforated axospinous synapses following hippocampal kindling is specific for the synaptic field of stimulated axons. Brain Res 507:325-331

Goddard GV, McIntyre D, Leech C (1969) A permanent change in brain function resulting from daily electrical stimulation. Exp Neurol 25:295-330.

Gruenthal M, Armstrong D, Ault B, Nadler JV (1986) Comparison of seizures and brain lesions produced by intracerebroventricular kainic acid and bicuculline methiodide. Exp Neurol 93:621-630.

Hansen A, Jorgensen OS, Bolwig TG, Barry DI (1990) Hippocampal kindling alters the concentration of glial fibrillary acidic protein and other marker proteins in rat brain. Brain Res 531:307-311.

Houser C, Miyashiro J, Swartz B, Walsh G, Rich J, Delgado-Escueta A (1990) Altered patterns of dynorphin immunoreactivity suggest mossy fiber reorganization in human hippocampal epilepsy. J Neurosci 10:267-282.

Jarvie PA, Logan TC, Geula C, Slevin JT (1990) Entorhinal kindling permanently enhances calcium dependent $\mathrm{L}$-glutamate release in regio inferior of rat hippocampus. Brain Res 508:188-193.

Laurberg S, Zimmer J (1981) Lesion-induced sprouting of hippocampal mossy fiber collaterals to the fascia dentata in developing and adult rats. J Comp Neurol 200:433-459.

Lothman E, Collins R, Ferrendelli J (1981) Kainic acid-induced limbic seizures: electrophysiologic studies. Neurology 31:806-812.

MacDonald RL, McLean MJ (1986) Anticonvulsant drugs: mechanisms of action. Adv Neurol 44:713-736.

McNamara JO (1984) Role of neurotransmitters in seizure mechanisms in the kindling model of epilepsy. Fed Proc 43:2516-2520.

Mody I, Stanton PK, Heinemann U (1988) Activation of $N$-methyl$D$-aspartate receptors parallels changes in cellular and synaptic properties of dentate gyrus granule cells after kindling. J Neurophysiol 59 1033-1053.
Mody I, Reynolds JN, Salter MW, Carlen PL, Macdonald JF (1990) Kindling-induced epilepsy alters calcium currents in granule cells of rat hippocampal slices. Brain Res 531:88-94.

Nadler JV, Cuthbertson G (1980) Kainic acid neurotoxicity toward hippocampal formation: dependence on specific excitatory pathways. Brain Res 195:47-56.

Nadler JV, Perry B, Gentry C, Cotman C (1980a) Degeneration of hippocampal CA3 pyramidal cells induced by intraventricular kainic acid. J Comp Neurol 192:333-359.

Nadler JV, Perry B, Cotman C (1980b) Selective reinnervation of hippocampal areas $\mathrm{CA} 1$ and the fascia dentata after destruction of CA3-CA4 afferents with kainic acid. Brain Res 182:1-9.

Represa A, Salle G, Ben-Ari Y (1989a) Hippocampal plasticity in the kindling model of epilepsy in rats. Neurosci Lett 99:345-350.

Represa A, Robain O, Tremblay E, Ben-Ari Y (1989b) Hippocampal plasticity in childhood epilepsy. Neurosci Lett 99:351-355.

Rouse-Brouwer K, Kostenbauder H, McNamara P, Blouin R (1984a) Phenobarbital in the genetically obese zucker rat. I. Pharmacokinetics after acute and chronic administration. J Pharmacol Exp Ther 231: 649-653.

Rouse-Brouwer K, Kostenbauder H, McNamara P, Blouin R (1984b) Phenobarbital in the genetically obese zucker rat. II. In vivo and in vitro assessments of microsomal enzyme induction. J Pharmacol Exp Ther 231:654-659.

Sater R, Nadler JV (1984) On the relation between seizures and brain lesions after intracerebroventricular kainic acid. Neurosci Lett 84:7378.

Sloviter R, Damiano B (1981) Sustained electrical stimulation of the perforant path duplicates kainate-induced electrophysiological effects and hippocampal damage in rats. Neurosci Lett 24:279-284.

Sloviter RS (1987) Decreased hippocampal inhibition and a selective loss of interneurons in experimental epilepsy. Science 235:73-76.

Sloviter RS (1992) Possible functional consequences of synaptic reorganization in the dentate gyrus of kainate treated rats. Neurosci Lett 137:91-96.

Stanton PK, Mody I, Heinemann U (1989) Down-regulation of norepinephrine sensitivity after induction of long-term neuronal plasticity (kindling) in the rat dentate gyrus. Brain Res 476:367-372.

Steward O, Cotman C, Lynch G (1973) Re-establishment of electrophysiologically functional entorhinal cortical input to the dentate gyrus deafferented by ipsilateral entorhinal lesions: innervation by the contralateral entorhinal cortex. Exp Brain Res 18:396-414.

Steward O, White W, Cotman C, Lynch G (1976) Potentiation of excitatory synaptic transmission in the normal and in the reinnervated dentate gyrus of the rat. Exp Brain Res 26:423-441.

Sutula T, Steward O (1986) Quantitative analysis of synaptic potentiation during kindling of the perforant path. J Neurophysiol 56:732745.

Sutula T, Harrison C, Steward O (1986) Chronic epileptogenesis induced by kindling of the entorhinal cortex: the role of the dentate gyrus. Brain Res 385:291-299.

Sutula TP, He XX, Hurtenbach C (1987) Facilitation of kindling by CA3-4 lesions: evidence for epileptogenic potential of lesion-induced sprouting and synaptic reorganization. Epilepsia 28:593.

Sutula T, He XX, Cavazos J, Scott G (1988) Synaptic reorganization in the hippocampus induced by abnormal functional activity. Science 239:1147-1150.

Sutula T, Cascino G, Cavazos J, Parada I, Ramirez L (1989) Mossy fiber synaptic reorganization in the epileptic human temporal lobe. Ann Neurol 26:321-330.

Sutula T, Golarai G, Cavazos J (1992) Assessing the functional significance of mossy fiber sprouting and synaptic reorganization. In: The dentate gyrus and its role in seizures. Epilepsy Research (suppl 7) (Ribak C, Gall C, Mody I, eds), pp 251-259. Amsterdam: Elsevier. Sutula TP (1990) Experimental models of temporal lobe epilepsy: new insights from the study of kindling and synaptic reorganization. Epilepsia 31[Suppl 3]:45-54.

Sutula TP, Cavazos JE, Golarai G (1990) Brief treatment with phenobarbital alters long-term susceptibility to kindling after CA3-4 lesions. Epilepsia 31:650.

Tauck D, Nadler JV (1985) Evidence of functional mossy fiber sprouting in hippocampal formation of kainic acid-treated rats. J Neurosci 5:1016-1022.

Wadman WJ, Heinemann U, Konnerth S, Neuhaus S (1985) Hippocampal slices of kindled rats reveal calcium involvement in epileptogenesis. Exp Brain Res 57:404-407. 
Wu K, Wasterlain C, Sachs L, Siekevitz P (1990) Effect of septal kindling on glutamate binding and calcium calmodulin-dependent phosphorylation in a postsynaptic density fraction isolated from rat cerebral cortex. Proc Natl Acad Sci USA 87:5298-5302.
Ylinen A, Miettinen R, Pitkanen A, Guylas A, Freund T, Riekkinen P (1991) Enhanced GABAergic inhibition preserves hippocampal structure and function in a model of epilepsy. Proc Natl Acad Sci USA 88:7650-7653. 